\title{
Spontaneous Recovery from Streptozotocin-Induced Diabetes in Rats Pretreated with Pertussis Vaccine or Hydrocortisone
}

\author{
T. Katada and M. Ui \\ Department of Physiological Chemistry, Faculty of Pharmaceutical Sciences, Hokkaido University, Sapporo, Japan
}

\begin{abstract}
Summary. Following the intravenous injection of streptozotocin into rats, postprandial hyperglycaemia was sustained from 24 hours over a subsequent period of some weeks and the rats were glucose intolerant. When streptozotocin was similarly injected into pertussis-sensitized or hydrocortisonetreated rats, the postprandial hyperglycaemia observed at 24 hours did not persist, but showed a progressive decline until near normoglycaemia was obtained a week later. These animals manifested normal glucose tolerance one week after streptozotocin. Thus, a spontaneous recovery from streptozotocin-induced diabetes occurred under these conditions. This spontaneous recovery from diabetes was associated with hyperinsulinaemia in the fed state.
\end{abstract}

Key words: Pertussis sensitization, hyperinsulinaemia, hydrocortisone, streptozotocin, glucose tolerance.

Streptozotocin produces diabetes in laboratory animals through the destruction of the pancreatic betacells. The diabetogenic activity of streptozotocin, however, is known to be modified by several agents; e.g., nicotinamide interferes with the development of diabetes by preventing streptozotocin-induced reduction in the pyridine nucleotide content of the pancreatic islets [1-3]. Other agents such as diazoxide [4] and adrenergic blockers [5] also produce resistance to streptozotocin.

During the course of recent studies with pertussis-sensitized rats [6], it was noticed that diabetes induced by streptozotocin in the pertussis rats was as severe as that in non-pertussis rats for two days, but became milder until normoglycaemia in the fed state was found after one week. Since the pertussis-sensitized rats are characterized by a strong insulin secretory response to various stimuli via the activation of beta-adrenergic receptors [7], the observed attenuation of diabetes appears to suggest an important role of insulin secretory activity or of adrenergic functions in the induction or prevention of postprandial hyperglycaemia. This is considered in the present paper.

\section{Materials and Methods}

Male rats of the Wistar-derived strain, weighing $180-250 \mathrm{~g}$, were used. In experiments in which periodical changes in blood glucose and plasma insulin were studied following streptozotocin injection, streptozotocin ( $5 \mathrm{mg}$ per $100 \mathrm{~g}$ body wt), freshly dissolved in citrate buffer $(\mathrm{pH} 4.5,0.1 \mathrm{~mol} / \mathrm{l})$, was injected intravenously into fasted rats (after a 20-h fast) at 10:00 a.m. Tail vein blood samples $(0.1 \mathrm{ml}$ each) were withdrawn to be analyzed for glucose [8] and for immunoreactive insulin [9] at 2, 4, 6 and 10 $h$ in the fasted state, and then 1,3 , and 7 days later at 10:00 hours while fed ad libitum.

Oral glucose tolerance tests were carried out by feeding a glucose solution (a $20 \%$ solution, $1 \mathrm{ml}$ per $100 \mathrm{~g}$ body wt) into 20 -h fasted rats through a stomach tube. Blood samples were taken for analysis of blood glucose at 15, 30,60 and $90 \mathrm{~min}$ after the glucose load.

Pertussis-sensitized rats were prepared by a single injection of Bordetella pertussis vaccine intraperitoneally $\left(2 \times 10^{10}\right.$ organisms per $100 \mathrm{~g}$ body wt) $[6,7]$. They were used 3 days later. Hydrocortisone acetate $(2.5 \mathrm{mg}$ per $100 \mathrm{~g}$ body wt) was injected subcutaneously $24 \mathrm{~h}$ and $3 \mathrm{~h}$ before the injec- 


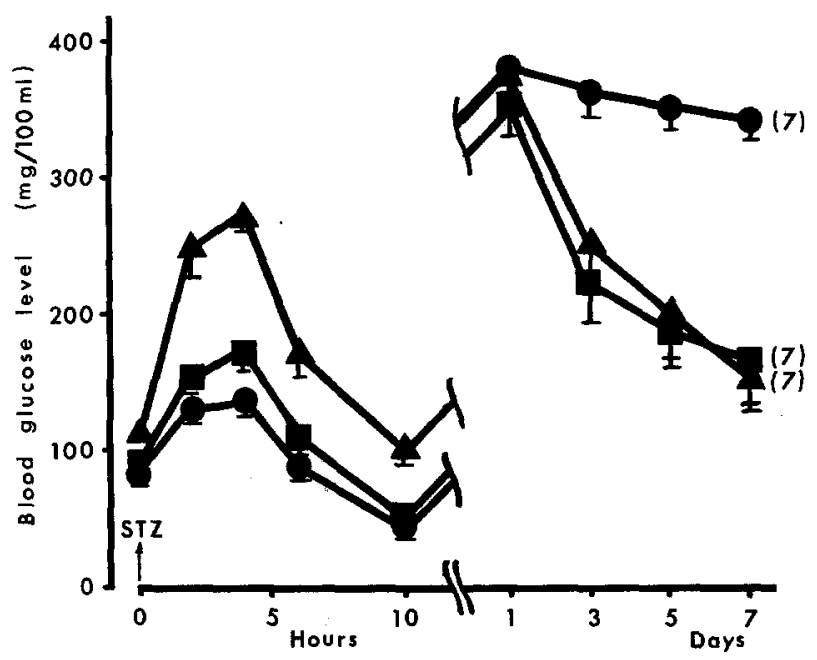

Fig. 1. Blood glucose level in control, pertussis-sensitized and hydrocortisone-treated rats after the injection of streptozotocin (STZ). - control, $\boldsymbol{\Delta}$ hydrocortisone-treated, $\mathbf{D}$ pertussis-sensitized. Mean values and SEM are given with numbers of observations in parentheses in this and following figures

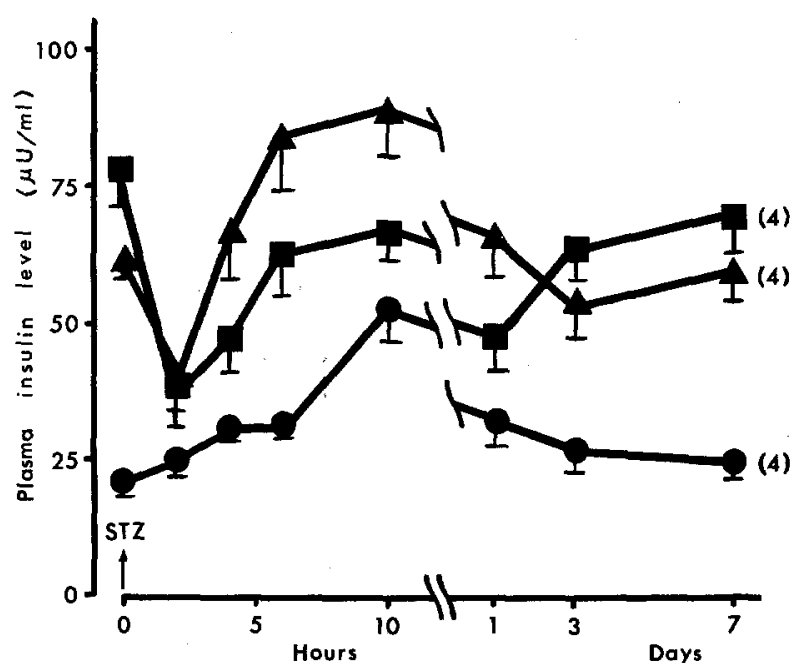

Fig. 2. Plasma insulin level in control, pertussis-sensitized and hydrocortisone-treated rats after the injection of streptozotocin (STZ). See legends to Figure 1 for explanation of symbols

tion of streptozotocin. Adrenalectomized rats were used one week after surgical extirpation of the adrenal glands by a dorsal approach. Acidotic rats were prepared by feeding $0.5 \mathrm{~mol} / 1 \mathrm{NH}_{4} \mathrm{Cl}$, as described previously [10].

The dose (per $100 \mathrm{~g}$ body wt), route and time (min before streptozotocin) of injections of various drugs into 20-h fasted rats were as follows. Insulin: $50 \mathrm{~m}$ units, subcutaneously, 6 injections at $2 \mathrm{~h}$ intervals (the first injection, $30 \mathrm{~min}$ before streptozotocin); glibenclamide: $50 \mu \mathrm{g}$, intraperitoneally, 6 injections (at the same time as insulin); propranolol: $3 \mathrm{mg}$, intraperitoneally, $30 \mathrm{~min}$; atropine: $100 \mu \mathrm{g}$, intraperitoneally, $30 \mathrm{~min}$; norepinephrine:
$100 \mu \mathrm{g}$, intraperitoneally, $30 \mathrm{~min}$; epinephrine: 50 $\mu \mathrm{g}$, intraperitoneally, $30 \mathrm{~min}$; nicotinamide: $25 \mathrm{mg}$, intraperitoneally, $15 \mathrm{~min}$.

Streptozotocin was obtained from two sources. A gift (lot No. 11837-GGS-22B) from Upjohn Company through the courtesy of Dr. W.E. Dulin was used in most of the experiments. Some experiments were carried out in the later part of this study with the preparation synthesized and donated by Dr. M. Yajima in Kakenyaku Kako Co., Ltd., Shiga, Japan. Sources of other reagents were: bovine crystalline insulin, Eli Lilly and Co. (Lot No. 615-D63-5) through the courtesy of Drs. O.K. Behrens and W.N. Shaw; glibenclamide, Yamanouch Pharmaceutical Co., Tokyo; propranolol, Ohtsuka Pharmaceutical Co., Tokushima; epineph rine tartrate, Merck; norepinephrine, atropine, hydrocortisone and nicotinamide, Sigma Chemical Co.

The difference between the means of blood glucose or plasma insulin was determined by Student's $t$ test [11]; differences were considered to be significant for $p<0.05$.

\section{Results}

Blood Glucose and Plasma Immunoreactive Insulin Levels in Normal, Pertussis-sensitized and Hydrocortisone-Treated Rats after the Injection of Streptozotocin

In accord with previous reports [12, 13], the injection of streptozotocin into rats induced hyperglycaemia over the first $4 \mathrm{~h}$, hypoglycaemia at 10 $\mathrm{h}$ and permanent hyperglycaemia after $24 \mathrm{~h}$ (Fig. 1). Fig. 2 shows that the hypoglycaemia observed at 10 $\mathrm{h}$ was associated with hyperinsulinaemia.

When pertussis-sensitized rats were submitted to the same treatment with streptozotocin, there was a similar glycaemic change over the period of $24 \mathrm{~h}$, but the hyperglycaemia occurring on the next day did not persist; the postprandial blood glucose level fell progressively toward the normal level in the following 6 days (Fig. 1). The fasting insulin level was 3 -fold higher in pertussis rats than in control rats (Fig. 2). Even after streptozotocin injection, the plasma insulin concentration was higher in pertussis rats than in control rats; the progressive recovery from hyperglycaemia from the first to 7 th day in pertussis rats was associated with maintenance of a plasma insulin level twice as high as in control rats.

Figures 1 and 2 show also the effect of streptozotocin on hydrocortisone-treated rats. Following streptozotocin, hydrocortisone-treated rats exhibited a similar triphasic glycaemic pattern, with the first peak of much larger magnitude. As in pertussis rats, 
the second hyperglycaemic phase was not permanent, but showed a progressive decline until near normoglycaemic levels were attained after 7 days. The plasma concentration of insulin was much higher in hydrocortisone-treated rats than in non-treated rats through the entire course of the experiment (Fig. 2).

\section{Oral Glucose Tolerance Tests 7 Days after Streptozotocin in Pertussis-sensitized or Hydrocortisone-Treated Rats}

Oral glucose tolerance tests were carried out 7 days after streptozotocin. Diabetes induced by $5 \mathrm{mg}$ of streptozotocin per $100 \mathrm{~g}$ body wt was so mild that there was no significant difference in the fasting level of blood glucose between streptozotocintreated and non-treated rats. The oral load of glucose caused a much more severe hyperglycaemia in streptozotocin-treated rats than in untreated rats $(p$ $<0.01$, Fig. 3). In the case of pertussis-sensitized or hydrocortisone-treated rats injected with streptozotocin, there was less hyperglycaemia over the 90 minutes following the glucose load, than in the control streptozotocin-diabetic rats. The blood glucose level at $\mathbf{1 5}$ and $\mathbf{3 0}$ minutes was only slightly higher than, and at 60 and 90 minutes essentially the same as, that in normal rats.

Thus, it is likely that pertussis-sensitized or hydrocortisone-treated rats had recovered from streptozotocin diabetes in 7 days.

\section{Development of Streptozotocin Diabetes under Various Conditions}

Rats were submitted to various treatments which might exert an influence on the pancreatic cells in such a manner as to be possibly inducible by pertussis sensitization or hydrocortisone therapy. Periodical changes of the blood concentration of glucose over 7 days after streptozotocin injection into these treated rats are summarized in Table 1 . It is seen that induction of acidosis, adrenalectomy, repeated injections of insulin or glibenclamide and a single injection of propranolol, atropine or norepinephrine were essentially without effect on development of streptozotocin-induced postprandial hyperglycaemia, though some of these treatments caused modification of the early changes in the blood glucose level up to 10 hours after streptozotocin. Nor were propranolol and adrenalectomy effective in modifying the pertussis- or hydrocortisone-induced spontaneous recovery from streptozotocin diabetes in 7 days. No hyperglycaemia developed, even in the first day of streptozotocin injection in nicotinamidetreated rats.

The only treatment that caused, like pertussis

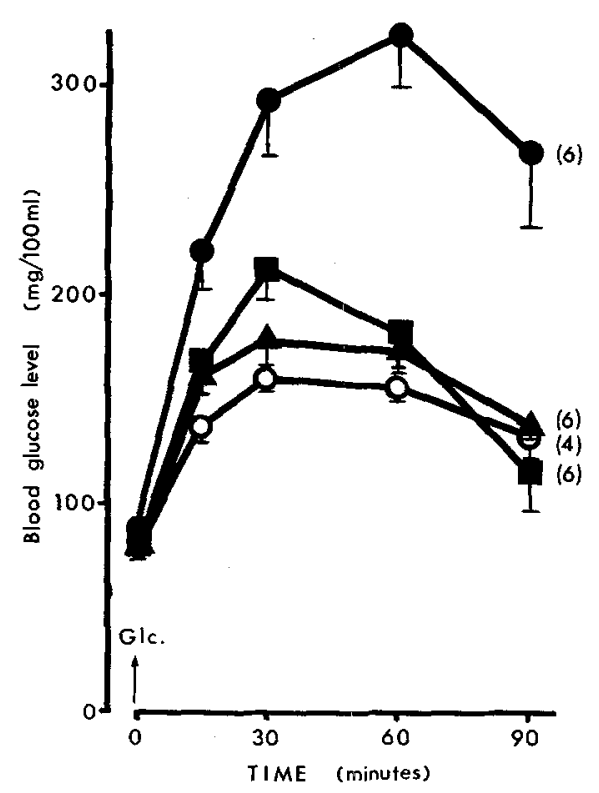

Fig. 3. Blood glucose level after oral glucose load. Glucose solution (Glc) was force-fed into fasted rats as shown by an arrow. $O$ : control rats not reated with streptozotocin. Solid symbols show the blood glucose level in streptozotocin-treated rats. They were used 7 days after the injection of streptozotocin. - control, $\Delta$ hydrocortisone-treated, $\boldsymbol{D}$ pertussis-sensitized

sensitization and hydrocortisone therapy, spontaneous recovery from streptozotocin hyperglycaemia was a single injection of epinephrine plus propranolol. There was a progressive decline of the blood glucose level over 7 days in the rats receiving epinephrine plus propranolol; the blood glucose concentration 7 days after streptozotocin (146 \pm 13 $\mathrm{mg} / 100 \mathrm{ml}$ ) was significantly lower than the value on the first day $(229 \pm 49)$ and than the value in the control diabetic rats on the same day $(375 \pm 24)$.

Plasma concentrations of insulin in the rats treated with epinephrine plus propranolol are recorded in Table 2 in comparison with the insulin concentrations in the control, acidotic, insulin-injected and glibenclamide-injected rats. Plasma insulin concentrations $1,3,5$ and 7 days after streptozotocin were significantly higher in the rats treated with epinephrine plus propranolol than in controls. This contrasts with the failure of other treatments (induction of acidosis, injection of insulin or glibenclamide) to cause significant hyperinsulinaemia during the same period.

Postprandial normoglycaemia observed in rats treated with epinephrine plus propranolol on the 7th day of streptozotocin injection may reflect a recovery from streptozotocin diabetes, because glucose intolerance induced by streptozotocin was no longer observable in these rats (Table 3). In contrast, neither induction of acidosis nor injection of glibenclamide resulted in amelioration of streptozotocin-induced glucose intolerance. 
Table 1. Blood glucose level after injection of streptozotocin. Experiments were carried out as described in Materials and Methods. Data in this and following tables are the mean \pm SEM with number of observations in parentheses

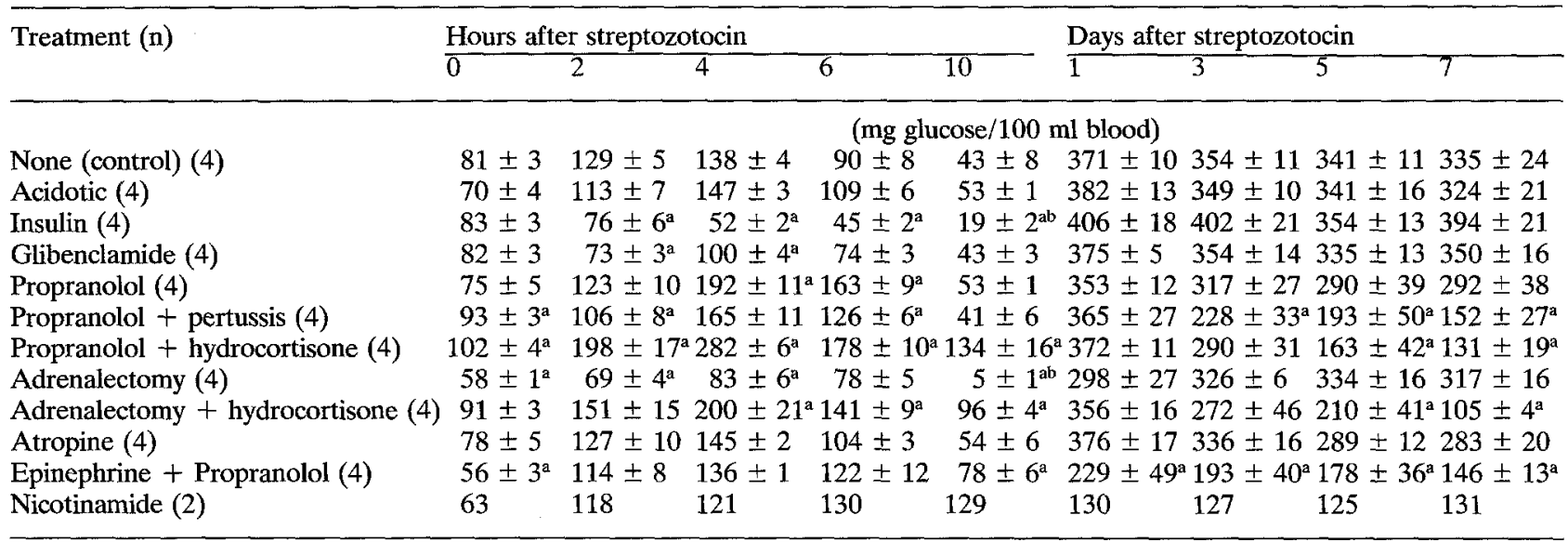

a Difference from the corresponding value of control rats is significant $(p<0.05)$

b Glucose was injected intravenously upon hypoglycaemic shock

Table 2. Plasma insulin level after injection of streptozotocin. Experimental conditions are the same as in Table 1

\begin{tabular}{|c|c|c|c|c|c|c|c|c|c|}
\hline \multirow[t]{2}{*}{ Treatment (n) } & \multicolumn{5}{|c|}{ Hours after streptozotocin } & \multicolumn{4}{|c|}{ Days after streptozotocin } \\
\hline & 0 & 2 & 4 & 6 & 10 & 1 & 3 & 5 & 7 \\
\hline & \multicolumn{9}{|c|}{ ( $\mu$ unit insulin /ml of plasma) } \\
\hline None (control) (4) & $21 \pm 2$ & $25 \pm 3$ & $31 \pm 2$ & $32 \pm 3$ & $52 \pm 4$ & $32 \pm 6$ & $27 \pm 5$ & $23 \pm 3$ & $25 \pm 4$ \\
\hline Acidotic (4) & $37 \pm 11$ & $36 \pm 10$ & $57 \pm 10^{a}$ & $69 \pm 6^{a}$ & $63 \pm 7$ & $27 \pm 4$ & $11 \pm 1^{\mathrm{a}}$ & $15 \pm 2$ & $14 \pm 3$ \\
\hline Insulin (4) & $13 \pm 3$ & $89 \pm 19^{a}$ & $115 \pm 8^{\mathrm{a}}$ & $176 \pm 23^{\mathrm{a}}$ & $86 \pm 24^{a}$ & $18 \pm 2$ & $16 \pm 3$ & $20 \pm 8$ & $32 \pm 9$ \\
\hline Glibenclamide (4) & $11 \pm 1^{\mathrm{a}}$ & $21 \pm 1$ & $14 \pm 1^{\mathrm{a}}$ & $25 \pm 1$ & $76 \pm 20$ & $22 \pm 4$ & $15 \pm 2$ & $20 \pm 3$ & $28 \pm 4$ \\
\hline Epinephrine + propranolol (4) & $7 \pm 1^{a}$ & $9 \pm 1^{\mathrm{a}}$ & $16 \pm 3^{\mathrm{a}}$ & $23 \pm 7$ & $43 \pm 6$ & $80 \pm 15^{\mathrm{a}}$ & $55 \pm 4^{\mathrm{a}}$ & $88 \pm 11^{\mathrm{a}}$ & $68 \pm 13^{a}$ \\
\hline
\end{tabular}

a The difference from the corresponding value of control rats is significant $(p<0.05)$

Table 3. Glucose tolerance pattern before and after streptozotocin. Glucose tolerance test was carried out as described in Materials and Methods. Streptozotocin was injected 7 days before experiment

\begin{tabular}{|c|c|c|c|c|c|}
\hline \multirow{2}{*}{$\begin{array}{l}\text { Treat- } \\
\text { ment (n) }\end{array}$} & \multicolumn{5}{|c|}{ Minutes after glucose load } \\
\hline & 0 & 15 & 30 & 60 & 90 \\
\hline & \multicolumn{5}{|c|}{ (mg glucose $/ 100 \mathrm{ml}$ of blood) } \\
\hline \multicolumn{6}{|c|}{ Before streptozotocin } \\
\hline $\begin{array}{l}\text { None } \\
\text { (normal) (4) } \\
\text { After strepto }\end{array}$ & $80 \pm 6$ & $139 \pm 8$ & $159 \pm 1$ & $155 \pm 1$ & $132 \pm 5$ \\
\hline $\begin{array}{l}\text { None } \\
\text { (control) (6) }\end{array}$ & $89 \pm 7$ & $220 \pm 28^{a}$ & $291 \pm 28^{\mathrm{a}}$ & $326 \pm 31^{\mathrm{a}}$ & a $267 \pm 38^{\mathrm{a}}$ \\
\hline $\begin{array}{l}\text { Aci- } \\
\text { dotic (4) }\end{array}$ & $92 \pm 5$ & $218 \pm 7^{\mathbf{a}}$ & $299 \pm 7^{\mathrm{a}}$ & $332 \pm 10^{a}$ & $293 \pm 16^{\mathrm{a}}$ \\
\hline $\begin{array}{l}\text { Gliben- } \\
\text { clamide (4) }\end{array}$ & $97 \pm 16$ & $5209 \pm 27^{a}$ & $275 \pm 30^{\mathrm{a}}$ & $317 \pm 26^{a}$ & $279 \pm 31^{a}$ \\
\hline $\begin{array}{l}\text { Epi- } \\
\text { nephrine }+ \\
\text { pro- } \\
\text { pranolol (4) }\end{array}$ & $71 \pm 3^{b}$ & $146 \pm 13^{\mathrm{b}}$ & $183 \pm 29^{\mathrm{b}}$ & $187 \pm 32^{b}$ & $\mathrm{~b} 167 \pm 22^{\mathrm{b}}$ \\
\hline
\end{tabular}

a Statistically significant is the difference from the normal tats not treated with streptozotocin $(p<0.05)$

b Statistically significant is the difference from the control rats $(p<0.05)$

\section{Discussion}

The present results clearly show that a unique transient diabetes develops following the administration of streptozotocin to rats pretreated with pertussis vaccine or hydrocortisone. In these animals, postprandial hyperglycaemia observed on the day after streptozotocin injection did not persist, and an almost normal nonfasting concentration of blood glucose and a normal glucose tolerance were observed after 7 days. This pattern is distinct from that observed in nicotinamide-treated rats in which no hyperglycaemia develops, even in the period immediately after streptozotocin. It is very likely, therefore, that different mechanisms underlie these two types of streptozotocin resistance. In this regard, pertussis- or hydrocortisone-treated rats resemble new-born rats, which also exhibit a rapid and spontaneous recovery from streptozotocin diabetes [14].

Severity of diabetes is known to depend on the dose of streptozotocin $[13,15,16]$. Diabetes induced by streptozotocin at the dose employed here was so mild that an overnight fast resulted in nor- 
moglycaemia despite an impaired glucose tolerance (Fig. 3). When the dose of streptozotocin was further increased, more severe diabetes developed with a marked hyperglycaemia even after prolonged fasting. Our unpublished observations show that there was no spontaneous recovery from such a severe diabetes even in pertussis-sensitized or hydrocortisone-treated rats. Thus, the degree of recovery is dependent on the severity of diabetes, in accordance with Portha et al. [14].

Pertussis-sensitized or hydrocortisone-treated rats are characterized by predominance of beta-adrenergic functions $[6,7,10]$. An involvement of enhanced beta-adrenergic activities in the spontaneous recovery from streptozotocin diabetes seems unlikely. The results in Table 1 indicate that beta-blockade, induced by propranolol, failed to prevent the progressive decline of postprandial hyperglycaemia over 7 days after streptozotocin injection to pertussis- or hydrocortisone-treated rats. Moreover, acidotic rats in which beta-adrenergic functions are somewhat increased [10] were not resistant to streptozotocin diabetes. On the contrary, a combined administration of a beta-blocking agent with epinephrine, like pertussis sensitization and hydrocortisone therapy, rendered the streptozotocin-induced postprandial hyperglycaemia of short duration. It is unlikely, therefore, that a particular adrenergic function is directly responsible for the spontaneous recovery from streptozotocin diabetes.

More insulin was secreted in response to streptozotocin from the pancreas of pertussis-sensitized or hydrocortisone-treated rats than from the pancreas of control rats (Fig. 2). A possible role of hyperinsulinaemia in causing a short-lived streptozotocin diabetes, however, is unlikely, because postprandial hyperglycaemia persisted even in the rats receiving repeated injections of insulin or glibenclamide immediately before and after the streptozotocin treatment. Conversely, a marked hypoinsulinaemia was induced by the treatment of rats with epinephrine plus propranolol (Table 2). Hypoinsulinaemia alone, however, may not play an important role in inducing the spontaneous recovery from streptozotocin diabetes in these rats, since neither adrenalectomy nor the injection of atropine or propranolol alone affected the duration of streptozotocin diabetes (Table 1) despite an early (up to 6 hours after streptozotocin) development of hypoinsulinaemia to a similar extent under these conditions (data not shown).

Thus, the mechanism by which mild diabetes induced by a lower dose of streptozotocin failed to persist in pertussis-sensitized or hydrocortisonetreated rats still remains to be elucidated, like the mechanism for the streptozotocin resistance induced by diazoxide $[4,17]$, which is currently a matter of debate.
Acknowledgements. We are very grateful to Dr. Y. Nakase, Department of Bacteriology, Kitasato Institute, Tokyo for his kind gift of pertussis vaccine.

\section{References}

1. Schein, P.S., Bates, R.W.: Plasma glucose levels in normal and adrenalectomized mice treated with streptozotocin and nicotinamide. Diabetes 17, 760-765 (1968)

2. Dulin, W.E., Wyse, B.M.: Studies on the ability of compounds to block the diabetogenic activity of streptozotocin. Diabetes 18, 459-466 (1969)

3. Anderson, T., Schein, P.S., McMenamin, M.G., Cooney, D. A.: Streptozotocin diabetes; Correlation with extent of depression of pancreatic islet nicotinamide adenine dinucleotide. J. Clin. Invest. 54, 672-677 (1974)

4. Culbert, S., Sharp, R., Rogers, M., Felts, P., Burr, I.M.: Diazoxide modification of streptozotocin-induced diabetes in rats. Diabetes 23, 282-286 (1974)

5. Iwatsuka, H., Shino, A., Taketomi, S.: Streptozotocin resistance of the genetically diabetic KK mouse. Diabetes 23 , 856-857 (1974)

6. Katada, T., Ui, M.: Accelerated turnover of blood glucose in pertussis sensitized rats due to combined actions of endogenous insulin and adrenergic beta-stimulation. Biochim. Biophys. Acta 421, 57-69 (1976)

7. Sumi, T., Ui, M.: Potentiation of the adrenergic beta-receptor-mediated insulin secretion in pertussis-sensitized rats. Endocrinology 97, 352-358 (1975)

8. Bergmeyer, H.-U., Bernt, E.: Glucose, determination with glucose oxidase and peroxidase. In: H. U. Bergmeyer (Ed.): Methods of enzymatic analysis, p. 123. New York: Academic Press 1963

9. Morgan, C. R., Lazarow, A.: Immunoassay of insulin; two antibody system: plasma insulin levels of normal, subdiabetic rats. Diabetes 12, 115-126 (1963)

10. Yajima, M., Ui, M.: Hydrocortisone restoration of the $\mathrm{pH}$ dependent metabolic responses to catecholamines. Am. J. Physiol. 228, 1053-1059 (1975)

11. Snedecor, G.W.: Statistical methods. Ames: Iowa State University Press 1956

12. Junod, A., Lambert, A.E., Orci, L., Pictet, R., Gonet, A. E., Renold, A. E.: Studies of the diabetogenic action of streptozotocin. Proc: Soc. Exp. Biol. Med. 126, 201-205 (1967)

13. Junod, A., Lambert, A.E., Stauffacher, W., Renold, A.E.: Diabetogenic action of streptozotocin: Relationship of dose to metabolic response. J. Clin. Invest. 48, 2129-2139 (1969)

14. Portha, B., Levacher, C., Picon, L., Rosselin, G.: Diabetogenic effect of streptozotocin in the rat during the perinatal period. Diabetes 23, 889-895 (1974)

15. Masiello, P., DePaoli, A., Bergamini, E.: Age-dependent changes in the sensitivity of the rat to a diabetogenic agent (streptozotocin). Endocrinology 96, 787-789 (1975)

16. Ganda, O.P., Rossini, A.A., Like, A.A.: Studies on streptozotocin diabetes. Diabetes 25, 595-603 (1976)

17. Burr, I.M., Marliss, E.B., Stauffacher, W., Renold, A.E.: Diazoxide effects on biphasic insulin release: "Adrenergic" suppression and enhancement in the perifused rat pancreas. J. Clin. Invest. 50, 1444-1450 (1971)

Received: February 25, 1977, and in revised form: May 16, 1977

Michio Ui

Department of Physiological Chemistry

Faculty of Pharmaceutical Sciences

Hokkaido University

Sapporo 060, Japan 